\title{
Analisa Nilai Tambah dari Produk Marning Jagung dan Emping Jagung
}

\section{The Value-Added Analysis of Product Marning Corn and Chips Corn}

\author{
Prasetyo Kurniawan', Muhammad Saikhu' ${ }^{2}$, Joko Gagung $S^{3}$ \\ ${ }^{1,2,3}$ Politeknik Pembangunan Pertanian Malang; Jl. Dr. Cipto 144a Bedali, Lawang- \\ Malang, Telp. 0341-427771/fax : 427774 \\ ${ }^{1,2,3}$ Penyuluhan Pertanian Berkelanjutan, Polbangtan Malang \\ e-mail: : ${ }^{1}$ prasetyokurniawan39@gmail.com, ${ }^{2}$ musaik09@gmail.com \\ 3jokojogas@gmail.com
}

\begin{abstract}
ABSTRAK
Jagung merupakan sumber energi tanaman di dunia yang mempunyai peranan penting, salah satunya dapat dijadikan alternatif sumber karbohidrat selain nasi. Di kalangan pelaku usaha bahan baku jagung, khususnya di Kelurahan Pandanwangi, Kecamatan Blimbing, Kota Malang sebagai sentra marning jagung dan emping jagung belum mengetahui pertambahan nilai antara produk marning jagung dan emping jagung yang di usahakan oleh mereka. Tujuan kajian ini adalah agar mengetahui nilai tambah antara produk marning jagung dan emping jagung dengan bahan baku jagung pipil. Analisis data dalam kajian ini menggunakan metode Hayami dengan menganalisis sebuah produk dalam satu kali produksi. Dari hasil kajian diperoleh data bahwa satu kali proses produksi marning mengalami penyusutan yang awal bahan baku pipil jagungnya sebanyak $500 \mathrm{~kg}$ menghasilkan produk $400 \mathrm{~kg}$ marning jagung dengan nilai tambah sebesar Rp. 20.748,00 sedangkan emping jagung yang awal baku pipil jagungnya sebanyak $500 \mathrm{~kg}$ menghasilkan produk $425 \mathrm{~kg}$ emping jagung dengan nilai tambah sebesar Rp. 37.682,00. Nilai tambah antara produk marning jagung dan emping jagung yang tertinggi, yaitu produk emping jagung, dikarenakan tenaga kerja dan sumbangan input lain yang dibutuhkan lebih rendah.
\end{abstract}

Kata kunci- Marning Jagung, Nilai Tambah, Emping Jagung

\section{ABSTRACT}

Corn is a source of plant energy in the world that has an important role, one of which can be used as an alternative source of carbohydrates besides rice. Among the business operators of corn raw materials, especially in Kelurahan Pandanwangi, Blimbing Subdistrict, Malang City as the center of corn marning and corn chips, they do not yet know the value added between the corn marning product and the corn chips that they have been working for. The purpose of this study is to determine the added value between corn marning products and corn chips with raw material for pipil corn. Data analysis in this study uses the Hayami method by analyzing a product in one production. From the results of the study obtained data that one time the marning production process experienced an initial shrinkage of $500 \mathrm{~kg}$ of corn corn raw material to produce $400 \mathrm{~kg}$ of corn marning products with an added value of Rp.20.748,00, while the initial corn chips were $500 \mathrm{~kg}$ of corn shells producing $425 \mathrm{~kg}$ of corn chips with 
added value of Rp. 37.682,00. The highest added value between corn marning products and corn chips, namely corn chips, is due to lower labor and other input contributions.

Keywords—Marning Corn, Value Added, Chips Corn

\section{PENDAHULUAN}

Jagung merupakan sumber energi tanaman di dunia yang mempunyai peranan penting, salah satunya dapat dijadikan alternatif sumber karbohidrat selain padi. Kota Malang di Jawa Timur memiliki potensi jagung sebagai wilayah penghasil jagung. Berdasarkan data dari Badan Pusat Statistik Dalam Angka 2019, luas tanam jagung tahun 2018 adalah seluas 65 hektar dan tahun 2018 seluas 99 hektar. Dari luas lahan itu, perkembangan luas panen jagung seluas 65 hektar pada 2017 dan pada tahun 2018 seluas 99 hektar. Di Kelurahan Pandanwangi terdapat kelompok tani yang mendiversifikasi jagung menjadi produk marning jagung dan emping jagung. Salah satu permasalahan yang dialami oleh pelaku usaha di kelompok tani ini adalah belum mengetahui nilai tambah dari produk yang mereka hasilkan. Nilai tambah adalah selisih dari nilai produk dengan nilai dari produk dengan harga bahan bakunya (Hayami et al,1987). Besarnya nilai tambah dari produk marning jagung dan emping jagung ditabulasikan menggunakan metode hayami.

\section{METODE PENELITIAN}

Kajian ini menggunakan salah satu metode, yaitu metode purposive sampling untuk penentuan samplingnya dan dilaksanakan di Kelompok Tani Teluk Bayur, Kelurahan Pandanwangi, Kecamatan Blimbing, Kota Malang pada bulan Desember 2019. Pertimbangan lokasi tersebut dipilih atas dasar bahwa di Kelurahan Pandanwangi merupakan sentra home industry marning jagung dan emping jagung. Responden yang digunakan pada kajian ini adalah 4 pelaku usaha dengan produk marning jagung dan emping jagung. Responden ini melakukan proses produksi dari bahan baku berupa jagung pipilan diolah menjadi produk makanan ringan yang telah digoreng dan telah diberi bumbu. Data primer diperoleh dari hasil wawancara ke anggota kelompok tani teluk bayur yang melakukan usaha marning jagung dan emping jagung untuk mendapatkan data, yaitu jumlah tenaga kerja, bahan baku yang dibutuhkan besaran input lainnya, harga jual dari produk dan hasil produksi jagung dengan menggunakan alat bantu berupa kuesioner. Data sekunder di dapatkan dari BPS dalam angka 2019, programa tingkat desa (kelurahan pandanwangi) yang didapatkan di kantor Dinas Pertanian Dan Ketahanan Pangan Kota Malang. Analisis yang digunakan untuk menghitung nilai tambah produk marning jagung dan emping jagung ini menggunakan metode hayami dengan menghitung satu kali produksi. Berikut ini adalah 
struktur analisis nilai tambah metode hayami dapat dilihat pada Tabel 1 .

Tabel 1. Analisis Nilai Tambah Hayami 1987

\begin{tabular}{|c|c|c|}
\hline No. & Variabel & Notasi \\
\hline \multicolumn{3}{|c|}{$\begin{array}{l}\text { A. Keluaran (output) masukan (Input) } \\
\text { dan harga }\end{array}$} \\
\hline 1. & $\begin{array}{l}\text { Output, } \quad \text { hasil } \\
\text { produksi (kg/proses) }\end{array}$ & $\mathrm{a}$ \\
\hline 2. & $\begin{array}{l}\text { Input, bahan baku } \\
\text { (kg/proses) }\end{array}$ & $\mathrm{b}$ \\
\hline 3. & $\begin{array}{l}\text { Input tenaga kerja } \\
(\mathrm{HOK} / \text { proses })\end{array}$ & $\mathrm{c}$ \\
\hline 4. & $\begin{array}{l}\text { Faktor konversi } \\
\text { output }\end{array}$ & $\mathrm{a} / \mathrm{b}=\mathrm{m}$ \\
\hline 5. & $\begin{array}{l}\text { Koefisien tenaga } \\
\text { kerja }(\mathrm{Rp} / \mathrm{kg})\end{array}$ & $\mathrm{c} / \mathrm{b}=\mathrm{n}$ \\
\hline 6. & $\begin{array}{l}\text { Harga } \\
(\mathrm{Rp} / \mathrm{Kg})\end{array}$ & $\mathrm{d}$ \\
\hline 7. & $\begin{array}{ll}\text { Tingkat } & \text { upah } \\
\text { tenaga } & \text { kerja } \\
(\mathrm{Rp} / \mathrm{Kg}) & \end{array}$ & $\mathrm{e}$ \\
\hline \multicolumn{3}{|c|}{ B. Output dan nilai tambah } \\
\hline & $\begin{array}{l}\text { Harga input }(\mathrm{Rp} / \mathrm{Kg} \\
\text { bahan baku }\end{array}$ & $\mathrm{f}$ \\
\hline 9. & $\begin{array}{l}\text { Sumbangan } \\
\text { lain (Rput } \\
\text { baku) }\end{array}$ & $\mathrm{g}$ \\
\hline 10. & $\begin{array}{l}\text { Nilai output }(\mathrm{Rp} / \mathrm{Kg} \\
\text { bahan baku }\end{array}$ & $\mathrm{m} \times \mathrm{d}=\mathrm{k}$ \\
\hline 11. & $\begin{array}{l}\text { Nilai } \quad \text { tambah } \\
(\mathrm{Rp} / \mathrm{Kg} \text { bahan baku) }\end{array}$ & $k-f-g=I$ \\
\hline
\end{tabular}

\section{HASIL DAN PEMBAHASAN}

Dalam menganalisis nilai tambah hayami terdapat beberapa variabel, yaitu hasil produksi (output), bahan baku pipil jagung (input), jumlah tenaga kerja, dan harga dari produk, upah rerata tenaga kerja, dan input lainnya yang mendukung kegiatan usaha tersebut.

Pada pengolahan marning dan emping jagung dibutuhkan bahan baku berupa jagung pipilan. Dari pipilan jagung sebanyak $500 \quad \mathrm{~kg}$ mengalami penyusutan sebesar $20 \%$ menjadi 400 $\mathrm{kg}$ produk marning jagung, sedangkan emping jagung mengalami penyusutan sebesar $15 \%$ menjadi $425 \mathrm{~kg}$ produk emping jagung dalam satu kali produksi. Biaya yang dibutuhkan dalam produksi marning jagung dan emping jagung dapat dilihat pada Tabel 2.

Tabel 2. Biaya Bahan Baku Dalam Produksi Marning Jagung Dan Emping Jagung

\begin{tabular}{|c|c|c|}
\hline \multirow{3}{*}{$\frac{\text { No }}{A}$} & Uraian & Keterangan \\
\hline & Bahan Baku & \\
\hline & Marning Jagung & \\
\hline 1 & Kebutuhan Jagung & 500 \\
\hline & Pipil (Kg) & \\
\hline 2 & $\begin{array}{l}\text { Biaya Pipil Jagung } \\
\text { (Rp/500kg) }\end{array}$ & 2.500 .000 \\
\hline 3 & $\begin{array}{l}\text { Harga Pipil Jagung } \\
(\mathrm{Rp} / \mathrm{Kg})\end{array}$ & 5.000 \\
\hline B & $\begin{array}{l}\text { Produksi Marning } \\
\text { Jagung }\end{array}$ & \\
\hline 1 & $\begin{array}{l}\text { Kebutuhan Produksi } \\
\text { Marning }(\mathrm{Kg})\end{array}$ & 400 \\
\hline 2 & $\begin{array}{l}\text { Biaya Marning } \\
\text { Jagung }(\mathrm{Rp} / 400 \mathrm{Kg})\end{array}$ & 5.200 .000 \\
\hline 3 & $\begin{array}{l}\text { Harga Marning } \\
\text { Jagung }(\mathrm{Rp} / \mathrm{Kg})\end{array}$ & 14.000 \\
\hline C & $\begin{array}{l}\text { Bahan Baku } \\
\text { Emping Jagung }\end{array}$ & \\
\hline 1 & $\begin{array}{l}\text { Kebutuhan Jagung } \\
\text { Pipil (Kg) }\end{array}$ & 500 \\
\hline 2 & $\begin{array}{l}\text { Biaya Pipil Jagung } \\
\text { (Rp/500kg) }\end{array}$ & 2.500 .000 \\
\hline 3 & $\begin{array}{l}\text { Harga Pipil Jagung } \\
(\mathrm{Rp} / \mathrm{Kg})\end{array}$ & 5.000 \\
\hline D & $\begin{array}{l}\text { Produksi Emping } \\
\text { Jagung }\end{array}$ & \\
\hline 1 & $\begin{array}{l}\text { Kebutuhan Produksi } \\
\text { Emping }(\mathrm{Kg})\end{array}$ & 425 \\
\hline 2 & $\begin{array}{l}\text { Biaya Emping } \\
\text { Jagung (Rp/425Kg) }\end{array}$ & 7.225 .000 \\
\hline 3 & $\begin{array}{l}\text { Harga Emping } \\
\text { Jagung }(\mathrm{Rp} / \mathrm{Kg})\end{array}$ & 17.000 \\
\hline
\end{tabular}


Rp. 5.200.000/400Kg atau Rp. $14.000 / \mathrm{Kg}$ produk marning jagung dan biaya produksi emping jagung sebesar Rp. $\quad 7.225 .000 / 425 \mathrm{Kg}$ atau Rp. $17.000 / \mathrm{Kg}$ produk emping jagung.

Variabel lainnya yang dibutuhkan, yaitu salah satunya tenaga kerja. Biaya tenaga kerja adalah balas jasa yang di berikan kepada karyawan atas produksi barang yang dihasilkan (Bastian,2010). Berikut ini adalah biaya tenaga kerja yang dibutuhkan dalam produksi marning jagung dan emping jagung dapat dilihat pada Tabel 3 .

Tabel 3. Biaya Tenaga Kerja Produksi Marning Jagung Dan Emping Jagung

\begin{tabular}{lll}
\hline No & Uraian & Keterangan \\
\hline A & Tenaga Kerja & \\
& Marning Jagung & \\
1 & Jumlah tenaga kerja & 8 \\
2 & Tiga Persiapan Bahan & 225.000 \\
& Baku (Rp/400kg) & \\
& Upah (Rp/kg) & 563 \\
3 & Tiga Pengolahan & 225.000 \\
& (Rp/400kg) & \\
& Upah (Rp/kg) & 563 \\
4 & $\begin{array}{l}\text { Dua Pengemasan } \\
\text { (Rp/400kg) }\end{array}$ & 100.000 \\
& Upah (Rp/kg) & 250 \\
$\mathbf{5}$ & Total & $\mathbf{1 . 3 7 5}$ \\
B & Tenaga Kerja Emping & \\
& Jagung & \\
1 & Jumlah tenaga kerja & 7 \\
2 & Dua Persiapan Bahan & 150.000 \\
& Baku (Rp/425kg) & \\
& Upah (Rp/kg) & 353 \\
3 & Tiga Pengolahan & 225.000 \\
& (Rp/425kg) & \\
& Upah (Rp/kg) & 530 \\
4 & Dua Pengemasan & 100.000 \\
& (Rp/425kg) & \\
Upah (Rp/kg) & 235 \\
5. & Total & $\mathbf{1 . 1 1 8}$ \\
\hline & &
\end{tabular}

Dari tabel di atas dapat diketahui bahwa jumlah tenaga kerja dalam produksi marning jagung sebanyak 8 orang, sedangkan emping jagung sebanyak 7 orang. Dari produksi marning tersebut dibutuhkan 3 orang dengan upah perharinya Rp. 225.000 untuk persiapan bahan baku atau Rp. 563/Kg produksi, 3 orang dengan upah perharinya $\mathrm{Rp}$. 225.000 untuk pengolahan atau Rp. 563/Kg produksi, 2 orang dengan upah perharinya Rp. 100.000 untuk pengemasan atau Rp. $250 / \mathrm{Kg}$ produksi.

Dalam memproduksi marning jagung dan emping jagung dibutuhkan alat dan mesin untuk mempercepat proses produksi, sehingga perlu adanya perhitungan untuk melihat biaya penyusutan yang dilihat dari umur ekonomisnya. Biaya penggunaan sendiri didapat dari masa efektif pekerja selama sebulan, yaitu 26 hari dikalikan dengan umur ekonomis dari alat dan mesin tersebut, sehingga diperoleh hasil 26 hari x 12 bulan x 10 tahun dengan jumlah 3.120 penggunaan. Untuk rincian biaya penyusutan alatnya dapat dilihat pada Tabel 4.

Tabel 4. Biaya Penyusutan Alat Dan

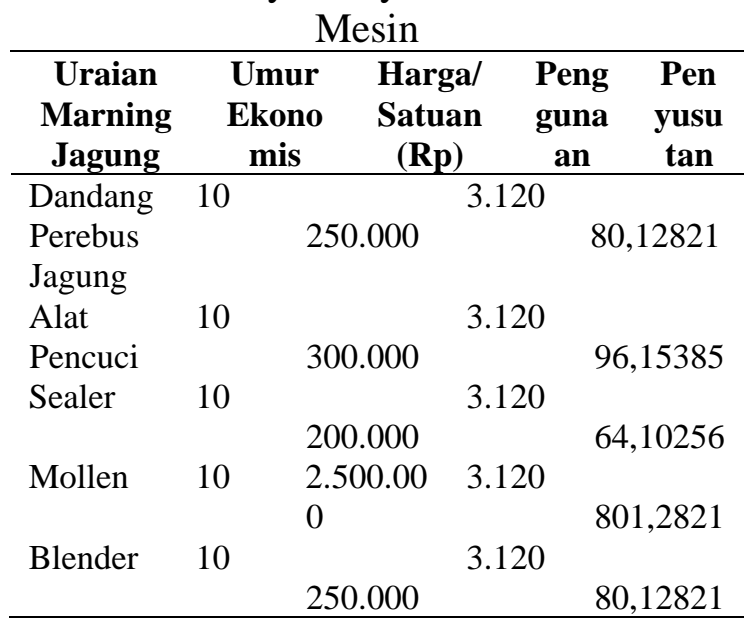




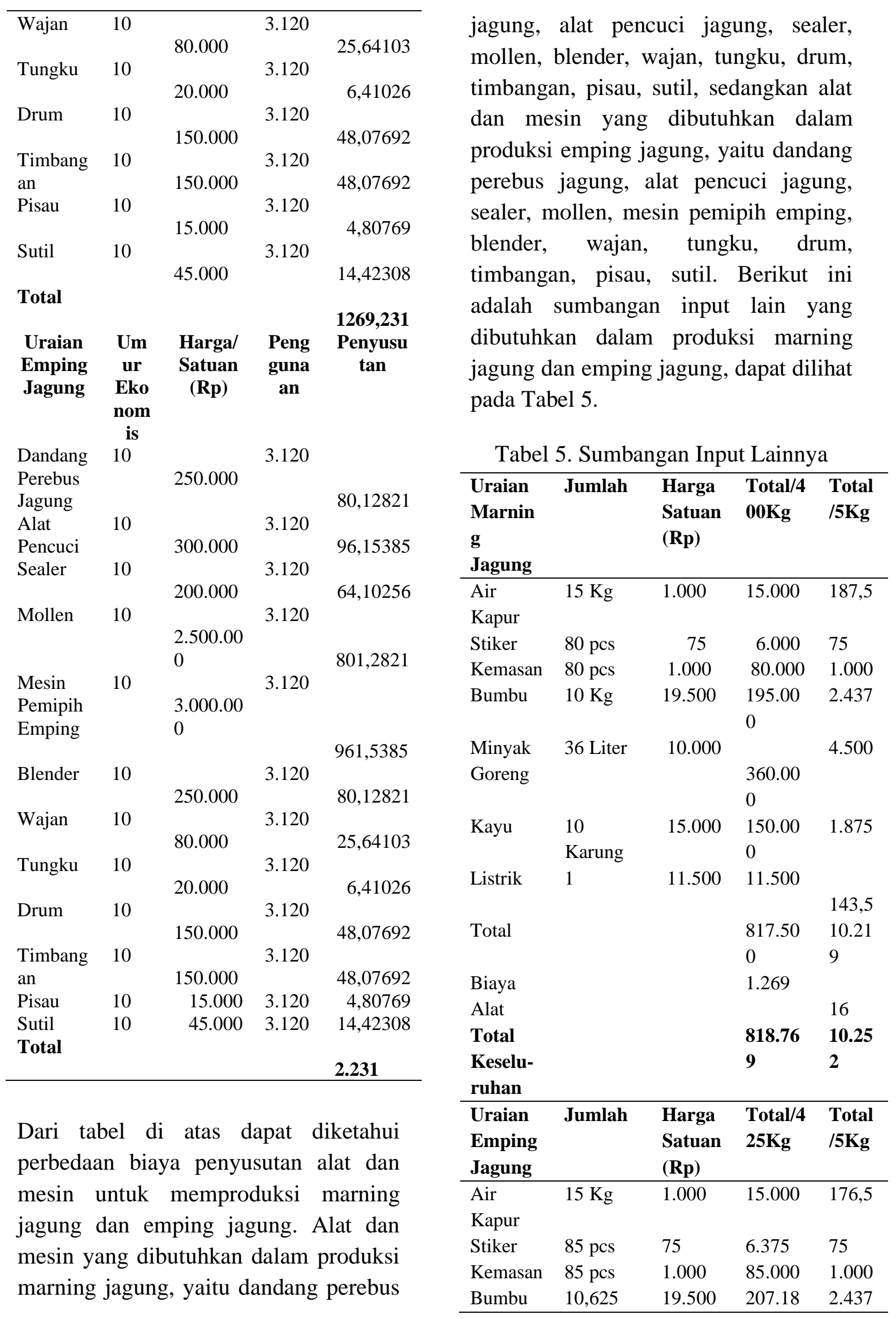




\begin{tabular}{lllll}
\hline & Kg & & 7,5 &, 5 \\
Minyak & 39,6 & 10.000 & 396.00 & 4.659 \\
Goreng & Liter & & 0 & \\
Kayu & 6 Karung & 15.000 & 90.000 & 1.059 \\
Listrik & 1 & 11.500 & 11.500 & 135 \\
Total & & & 801.06 & 9.542 \\
& & & 3 & \\
Biaya & & 2.231 & 26 \\
Alat & & & & \\
Total & & & $\mathbf{8 0 3 . 2 9}$ & $\mathbf{9 . 5 6 8}$ \\
Keselur & & $\mathbf{4}$ & \\
uhan & & & & \\
\hline
\end{tabular}

Dari Tabel 5. Dapat diketahui bahwa sumbangan input untuk produksi marning jagung dan emping jagung sebagai bahan tambahan yang diperlukan dalam satu kali produksi. Sumbangan input lainnya produk marning jagung dibutuhkan biaya sebesar Rp. 10.252/5 Kg dan produk emping jagung dibutuhkan biaya sebesar Rp. 9.568/ 5 Kg. Dari data di atas, kemudian dapat dihitung nilai tambah antara produk marning jagung dan emping jagung yang dapat dilihat pada Tabel 6.

Tabel 6. Perhitungan Nilai Tambah Dalam 1 Kali Produksi Marning Jagung Dan Emping Jagung

\begin{tabular}{lllll}
\hline No & \multicolumn{1}{c}{ Variabel } & Notasi & $\begin{array}{c}\text { Marning } \\
\text { Jagung }\end{array}$ & $\begin{array}{c}\text { Emping } \\
\text { Jagung }\end{array}$ \\
\hline A & $\begin{array}{l}\text { Output, } \\
\text { Input, Harga }\end{array}$ & & & \\
1 & $\begin{array}{l}\text { Output, Hasil } \\
\text { Produksi } \\
\text { (Kg/proses) }\end{array}$ & a & 400 & 425 \\
2 & $\begin{array}{l}\text { Input, Bahan } \\
\text { baku } \\
\text { (Kg/proses) }\end{array}$ & b & 500 & 500 \\
3 & $\begin{array}{l}\text { Input tenaga } \\
\text { kerja } \\
\text { (HOK/proses) }\end{array}$ & c & 8 & 7 \\
4 & $\begin{array}{l}\text { Faktor } \\
\text { konversi }\end{array}$ & a/b=m & 0,8 & 0,85 \\
\hline
\end{tabular}

Dari Tabel 6. Dapat diketahui bahwa untuk membuat produk marning jagung $400 \mathrm{Kg}$ membutuhkan bahan baku jagung pipil sebanyak $500 \mathrm{Kg}$, faktor konversinya 0,8 untuk marning jagung dari hal tersebut menunjukkan bahwa 1 $\mathrm{Kg}$ pipil jagung menghasilkan marning jagung sebanyak 0,8 Kg. Sedangkan untuk membuat produk emping jagung $425 \mathrm{Kg}$ membutuhkan bahan baku pipil sebanyak $500 \mathrm{Kg}$ dengan faktor konversi 0,85 yang menunjukkan bahwa $1 \mathrm{Kg}$ bahan baku jagung pipil menghasilkan $0,85 \mathrm{Kg}$ emping jagung. Untuk jumlah 8 HOK marning jagung dengan upah rerata kerja Rp. 6.875/ 5kg bahan baku, sedangkan jumlah HOK emping jagung adalah 7 HOK dengan upah rerata tenaga kerja sebesar Rp. 5.590/5kg. Pipil jagung sebagai bahan 
baku utama dalam pembuatan marning jagung dan emping jagung seharga Rp.5.000/Kg dan menghasilkan harga output sebesar Rp. 14.000/Kg marning jagung dan Rp. 17.000/Kg emping jagung, sedangkan untuk sumbangan input lainnyayang diperlukan dalam produksi marning jagung dan emping jagung, yaitu air kapur, stiker, kemasan, bumbu, kayu bakar, minyak goreng, listrik, tenaga kerja dan penyusutan. Sumbangan input lain untuk marning jagung, yaitu sebesar Rp. 10.252/5kg dan sumbangan input lain untuk emping jagung sebesar Rp. $9.568 / 5 \mathrm{~kg}$.

Sehingga dari data di atas dapat diketahui bahwa nilai tambah untuk pengolahan emping jagung yang mempunyai nilai tambah yang tinggi, yaitu sebesar Rp.37.682/5kg, sedangkan nilai tambah pengolahan marning jagung, yaitu sebesar Rp. 20.748/5Kg.

\section{KESIMPULAN}

1. Nilai tambah produk marning jagung sebesar Rp. 37.682/5 Kg, sedangkan nilai tambah produk emping jagung sebesar Rp. $20.748 / 5 \mathrm{Kg}$.

2. Nilai tambah antara produk marning jagung dan emping jagung yang tertinggi, yaitu produk emping jagung.

3. Nilai tambah tertinggi pada produk emping jagung dikarenakan jumlah tenaga kerja yang dibutuhkan lebih sedikit dan sumbangan input lain yang dibutuhkan lebih rendah.

\section{SARAN}

Perlu adanya survei pasar terkait dengan harga mesin produksi, dikarenakan harga mesin pada saat wawancara berbeda antara responden satu dengan yang lainnya.

\section{DAFTAR PUSTAKA}

Badan Pusat Statistik. 2019. Malang Dalam Angka. BPS Kota Malang.

Bastian, Indra. 2010. Akuntansi Sektor Publik Edisi Ketiga. Jakarta: Erlangga.

Hayami Y., Thosinori, M., dan Masdjidin S. 1987. Agricultural Markerting and Processing in Upland Java: A prospectif From A Sunda Village, Bogor 